\title{
Enxerto auricular autógeno em reparo de fratura blow-out
}

\author{
Auricular autograft in blow-out fracture repair \\ Injerto auricular autógeno en la reparación de la fractura blow-out
}

\author{
Murilo Moura OLIVEIRA ${ }^{1}$ \\ Ellen Cristina GAETTI JARDIM ${ }^{2}$ \\ Janayna Gomes PAIVA OLIVEIRA ${ }^{3}$ \\ Danilo Chizzolini MASOCATTO ${ }^{1}$ \\ Cauê Monteiro dos SANTOS ${ }^{4}$ \\ Fernando Ribeiro TEIXEIRA ${ }^{4}$ \\ Juliana Andrade MACENA ${ }^{4}$ \\ José Carlos Garcia de MENDONÇA ${ }^{5}$
}

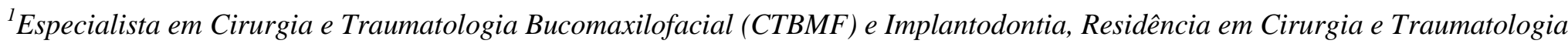 \\ Bucomaxilofacial, Hospital Universitário "Maria Aparecida Pedrossian" Universidade Federal do Mato Grosso do Sul, UFMS, \\ Campo Grande - MS, Brasil \\ ${ }^{2}$ Especialista em Cirurgia e Traumatologia Bucomaxilofacial e Estomatologia/ Mestre, Doutora e Pós-Doutora em Cirurgia e Traumatologia \\ Bucomaxilofacial pela Universidade Estadual Paulista Júlio de Mesquita Filho - UNESP / Professora Adjunto de Cirurgia e Traumatologia \\ Bucomaxilofacial da FAODO - UFMS, Campo Grande - MS, Brasil \\ ${ }^{3}$ Especialista em Cirurgia e Traumatologia Bucomaxilofacial / Mestre em Ciências da Saúde pela Faculdade de Medicina da \\ Universidade Federal do Mato Grosso do Sul - UFMS, Campo Grande - MS, Brasil \\ ${ }^{4}$ Residente em Cirurgia e Traumatologia Bucomaxilofacial, Hospital Universitário "Maria Aparecida Pedrossian" \\ Universidade Federal do Mato Grosso do Sul, UFMS - Campo Grande - MS, Brasil \\ ${ }_{5}^{5}$ Especialista em Cirurgia e Traumatologia Bucomaxilofacial / Mestre e Doutor em Ciências da Saúde pela Faculdade de Medicina da \\ Universidade Federal do Mato Grosso do Sul, UFMS - Campo Grande - MS, Brasil \\ Professor Adjunto de Cirurgia e Traumatologia Bucomaxilofacial da FAODO - UFMS \\ Coordenador do Programa de Residência em Cirurgia e Traumatologia Bucomaxilofacial do Hospital Universitário "Maria Aparecida Pedrossian" \\ Universidade Federal do Mato Grosso do Sul, UFMS - Campo Grande - MS, Brasil
}

\section{Resumo}

O assoalho orbital é um dos locais mais comumente acometidos nas fraturas faciais, podendo se apresentar como fratura de assoalho pura ou como parte de outras fraturas do terço médio da face. Sendo assim foi realizado um relato de caso de paciente vítima de acidente motociclístico que apresentava equimose periorbitária do lado esquerdo, degrau ósseo em pilar zigomáticomaxilar ipsilateral assim como parestesia infra-orbital do mesmo lado. Ao exame oftalmológico, a acuidade visual, a motilidade ocular e o reflexo fotomotor estavam preservados, ausência de diplopia e enoftalmia. Foi constatado clinica e imaginologicamente fratura de assoalho orbital, sutura fronto-zigomática, pilar zigomático-maxilar, pilar canino esquerdo e septo nasal. Foi então realizado sob anestesia geral a redução e fixação das fraturas mencionadas meio do acesso subtarsal para a fratura orbital, associada a enxerto de cartilagem auricular removido no mesmo ato cirúrgico. Em pós-operatórios de 15 dias, 7 meses e 9 meses aspectos de normalidade e processo normal de cicatrização foram observados assim como manutenção da acuidade e motilidade ocular mantiveram-se preservados.

Descritores: Fraturas Ósseas; Cartilagem da Orelha; Transplante.

\begin{abstract}
The orbital floor is one of the most commonly affected sites in facial fractures, which may present as pure floor fracture or as part of other middle third fractures of the face. So we conducted a case report of a patient victim of motorcycle accident that had periorbital ecchymosis on the left, bony step in zygomaticomaxillary ipsilateral pillar as well as infra-orbital parestesia the same side. On examination, visual acuity, ocular motility and reflection fotomotor were preserved, no diplopia and enophthalmos. clinical and imaginologicamente orbital floor fracture, fronto-zygomatic suture, zygomaticomaxillary pillar, left canine pillar and nasal septum was found. It was then performed under general anesthesia reduction and fixation of fractures mentioned through subtarsal access to orbital fracture associated with auricular cartilage graft removed during the same operation. At 15 days postoperatively 7 months and 9 months aspects of normality and normal healing process were observed as well as maintenance of visual acuity and ocular motility remained preserved.
\end{abstract}

Descriptors: Bone Fractures; Ear Cartilage; Transplant.

\section{Resumen}

El piso de la órbita es uno de los sitios más comúnmente afectados en las fracturas faciales, que se puede presentar como fractura de piso pura o como parte de otras fracturas del tercio medio de la cara. Fue realizado un relato de caso de paciente víctima de accidente en motocicleta, que presentaba equimosis periorbitaria del lado izquierdo, escalón óseo en la unión cigomático-maxilar ipsilateral, así como parestesia infra-orbital del mismo lado. En el examen oftalmológico, la agudeza visual, la motilidad ocular y reflejo fotomotor estaban preservados, con ausencia de diplopía y exoftalmos. Fue constatada fractura clínica y radiológicamente del piso de orbita, de la sutura fronto-cigomática, de la unión cigomático-maxilar, del pilar del canino izquierdo y septum nasal. Fue realizada la reducción y fijación de las fracturas mencionadas bajo anestesia general, mediante un acceso subciliar para la fractura orbital asociado a un injerto de cartílago auricular removido durante la misma cirugía. En el pos-operatorio de 15 días, 7 meses y 9 meses se observaron aspectos de normalidad y proceso normal de cicatrización, así como el mantenimiento de la agudeza visual y la motilidad ocular preservados.

Descriptores: Fracturas Óseas; Cartílago de la Oreja; Trasplante. 


\section{INTRODUÇÃO}

O assoalho orbital (AO) é um dos locais mais comumente acometidos nas fraturas faciais, podendo se apresentar como fratura de assoalho pura ou como parte de outras fraturas do terço médio da face ${ }^{1,2}$. A faixa etária mais frequentemente acometida é a terceira década de vida ${ }^{3}$. Defeitos estéticos e funcionais são frequentes quando tal comorbidade é negligenciada ou tratada inadequadamente ${ }^{4}$.

Os achados clínicos incluem equimose e edema periorbital, restrição de movimentação ocular, diminuição da acuidade visual, diplopia, enoftalmia, hipoestesia ou anestesia infra-orbital ${ }^{5}$.

O diagnóstico por imagem utiliza-se de radiografia em incidências póstero-anterior e mento-naso, porém o padrão ouro é a tomografia computadorizada (TC) especialmente em cortes coronal e sagital ${ }^{6,7}$.

Dependendo do tamanho do defeito, uma abordagem cirúrgica pode ser necessária. As fissuras muitas vezes podem ser tratadas de forma conservadora, enquanto que fraturas cominutivas e defeitos maiores requerem cirurgia para reconstrução do assoalho ${ }^{8,9}$.

A seleção do material para reconstrução do $\mathrm{AO}$ está relacionada a diversos fatores, como: tamanho do defeito, paredes envolvidas, adaptação dos contornos internos, restauração do volume apropriado, tempo decorrido do trauma e experiência do cirurgião ${ }^{10}$. Dentre tais materiais se destacam os autógenos (osso e cartilagem) e os aloplásticos (titânio, polietileno poroso e polidioxanona) ${ }^{11}$.

Materiais aloplásticos devem ser utilizados com cautela, uma vez que aumentam o risco de infecção e têm potencial para a extrusão ${ }^{12}$. Os enxertos autógenos tem sido a preferência de grande parte dos cirurgiões, devido a sua eficácia e baixo indice de complicações ${ }^{13}$. Dentre os enxertos autógenos mais utilizados, a cartilagem auricular configura-se como um tecido hipovascularizado e requer assim pouca perfusão sanguínea, o que significa menor índice de reabsorção quando comparada ao enxerto livre de osso autógeno ${ }^{14}$.

Deste modo, tendo em vista o tratamento das fraturas em $\mathrm{AO}$, o presente trabalho tem por objetivo relatar um caso clínico no qual foi utilizado um enxerto livre de cartilagem auricular no reparo de um defeito de assoalho.

\section{CASO CLÍNICO}

Paciente 40 anos, gênero masculino, feoderma, vítima de acidente motociclístico, procurou Hospital Universitário Maria Aparecida Pedrossian da Universidade Federal do Mato Grosso do Sul, com trauma em membros inferior esquerdo e face lado esquerdo, após 7 dias do acidente. O paciente foi internado pela equipe de ortopedia, a qual realizou o tratamento da fratura de membro inferior através da redução e imobilização com gesso. Em seguida o paciente foi encaminhado ao Serviço de Cirurgia e Traumatologia Bucomaxilofacial. Ao exame clínico extraoral, o paciente apresentava equimose periorbitária do lado esquerdo. A palpação observou-se degrau ósseo em pilar zigomático-maxilar do lado esquerdo. $\mathrm{O}$ paciente relatava parestesia infra-orbital do lado esquerdo e ausência de epistaxe e dificuldade de respiração. Ao exame oftalmológico, a acuidade visual, a motilidade ocular e o reflexo fotomotor estavam preservados, ausência de diplopia e enoftalmia. Ao exame tomográfico, em corte coronal e sagital (Figura 1) constatou-se fratura de $\mathrm{AO}$, sutura frontozigomática, pilar zigomaticomaxilar, pilar canino esquerdo e septo nasal.

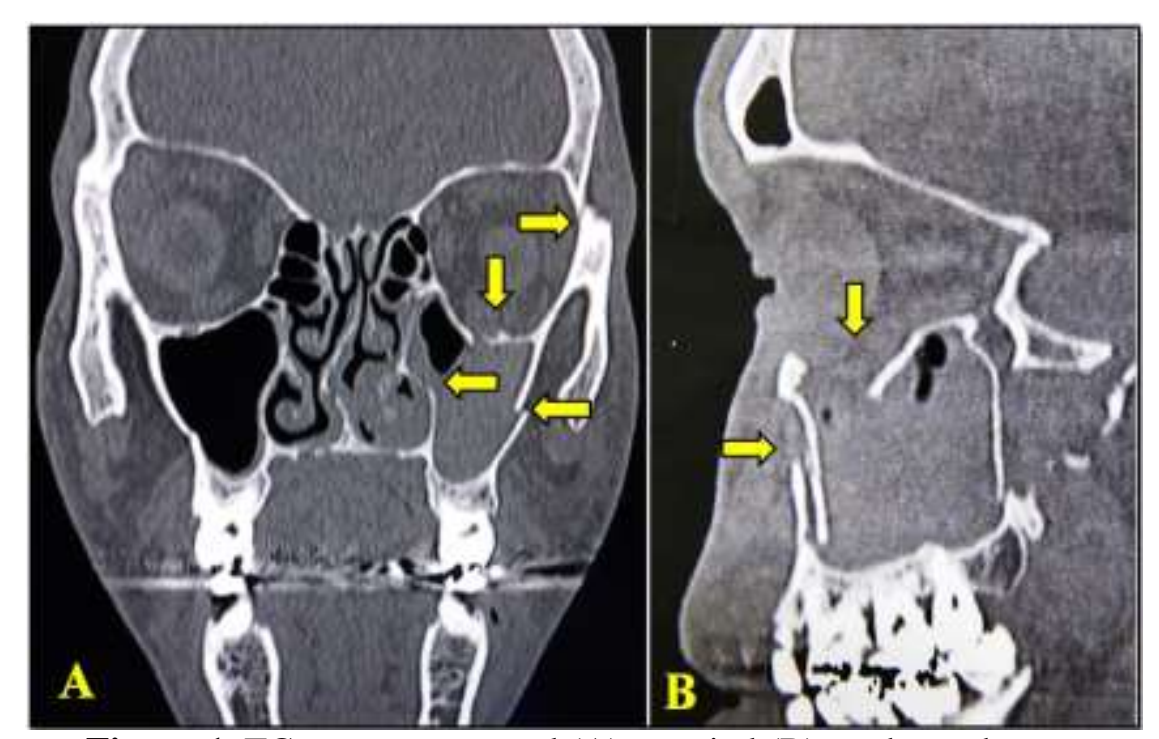

Figura 1. TC em corte coronal (A) e sagital (B), onde se observa fraturas de $\mathrm{AO}$, sutura frontozigomática, pilar zigomaticomaxilar, pilar canino esquerdo e septo nasal (setas)

O procedimento cirúrgico foi realizado sob anestesia geral, a fratura de assoalho foi exposta por meio do acesso subtarsal, onde foi possível observar um defeito ósseo de aproximadamente $2 \mathrm{~cm}^{2}$ (Figura 2). A fratura nasal foi reduzida e a do pilar zigomático-maxilar foi reduzida e fixada com 2 placas e parafusos de titânio do sistema $2.0 \mathrm{~mm}$.

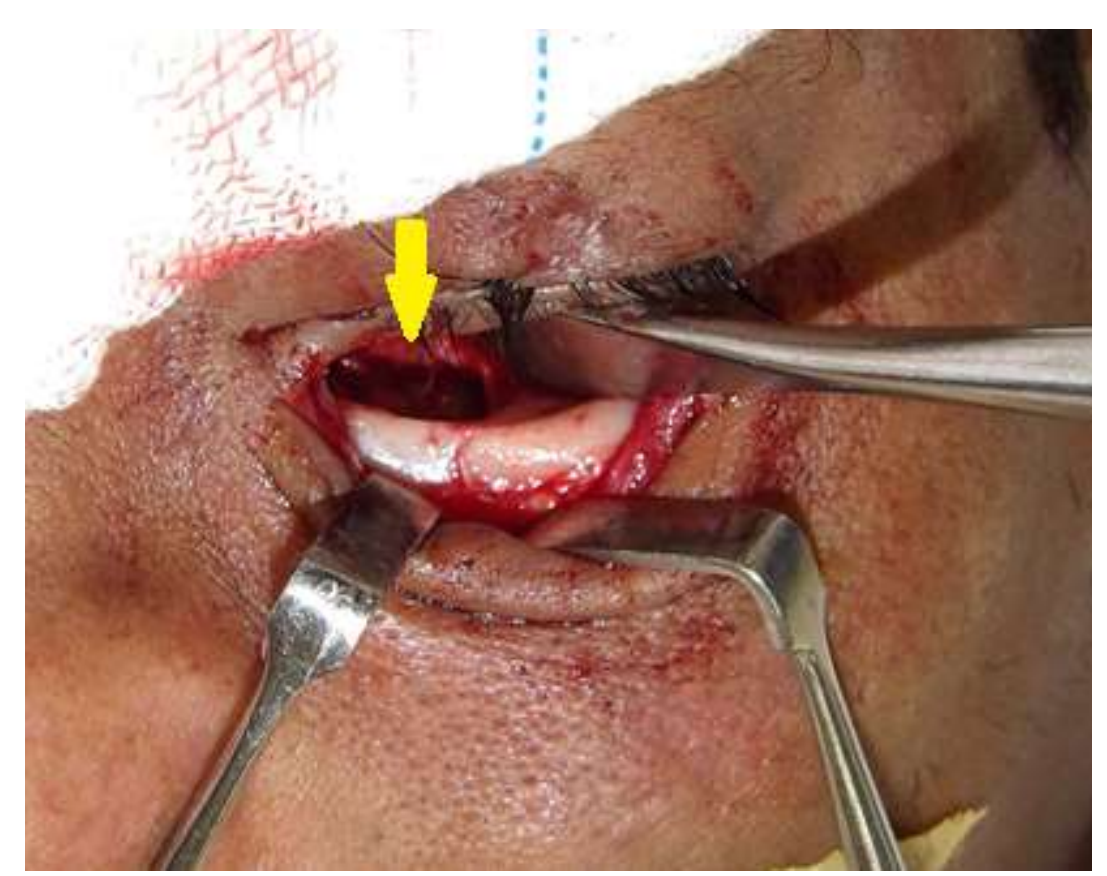

Figura 2. Acesso subtarsal expondo o defeito de AO (seta)

Para reconstrução do defeito ósseo do $\mathrm{AO}$, foi confeccionado um template para se estabelecer as 
corretas dimensões do enxerto a ser removido. O acesso retroauricular foi realizado no ângulo cefaloconchal. $\mathrm{O}$ template foi alocado na cartilagem (Figura 3) prosseguindo-se a remoção do enxerto (Figura 4). O enxerto foi posicionado na área receptora onde se manteve estabilizado pelo próprio peso do globo ocular (Figura 5). As suturas foram realizadas e um curativo compressivo foi realizado na área doadora, com intuito de prevenir hematoma pós-operatório.

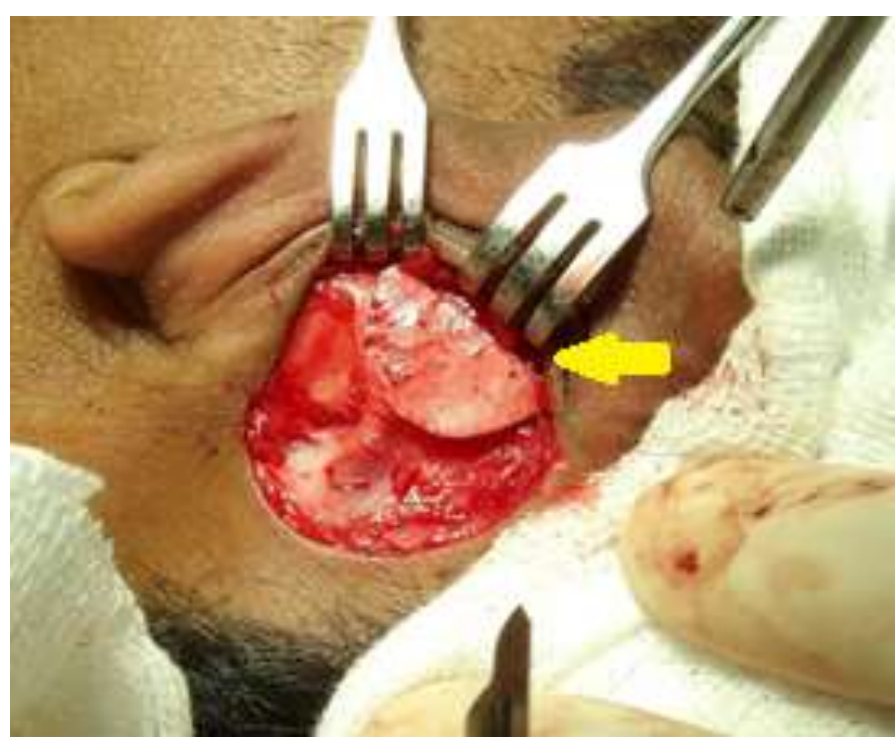

Figura 3. Template posicionado sobre a cartilagem auricular (seta)

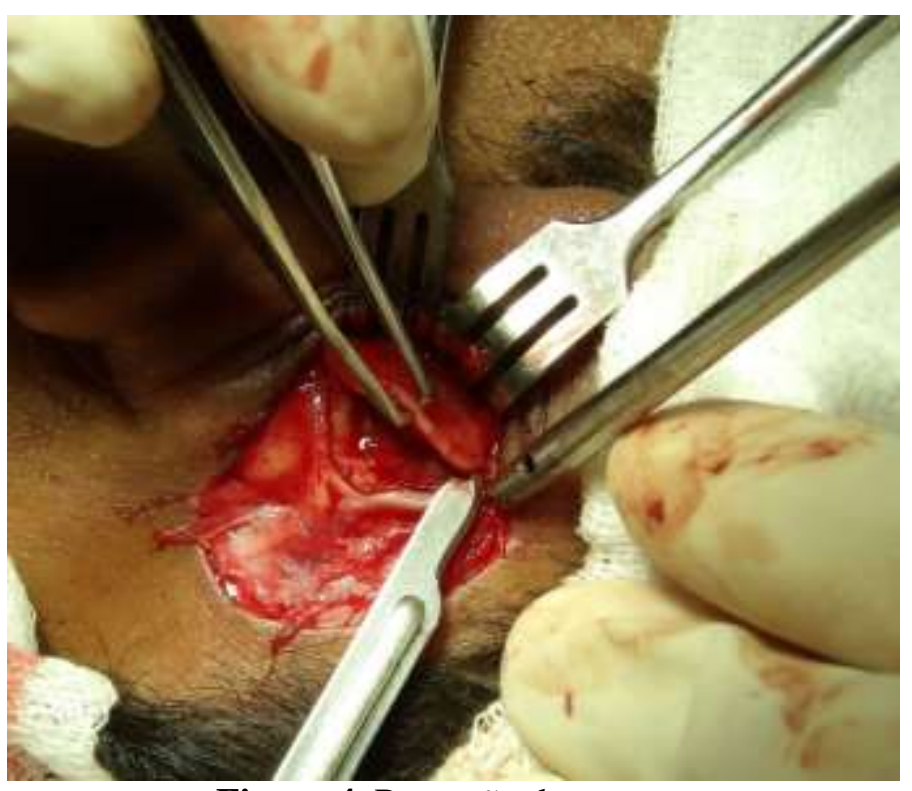

Figura 4. Remoção do enxerto

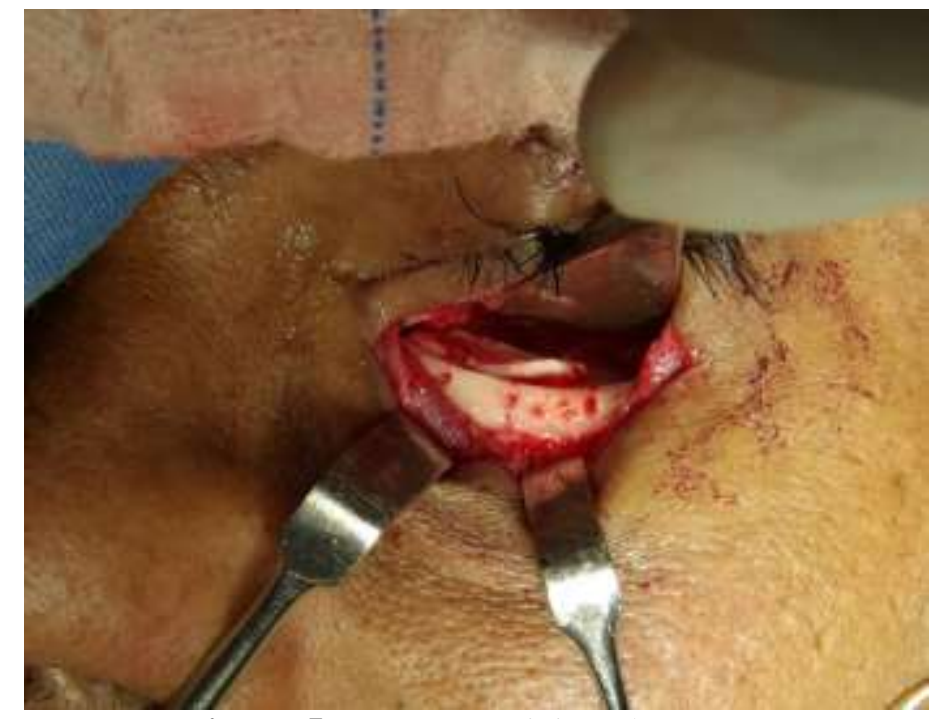

Figura 5. Enxerto posicionado no AO

No pós-operatório de 15 dias, o paciente se encontrava sem sinais e sintomas de infecção, sem queixas álgicas, diplopia ou enoftalmia, e satisfatório processo de cicatrização, com presença de discreto edema infra-orbitário compatível com o procedimento cirúrgico. Ao $7^{\circ}$ mês de pós-operatório o paciente apresentava satisfatória cicatrização, ausência de restrição de motilidade ocular (Figura 6), ausência de enoftalmia ou diplopia e sem alterações estéticas no pavilhão auricular (Figura 7).

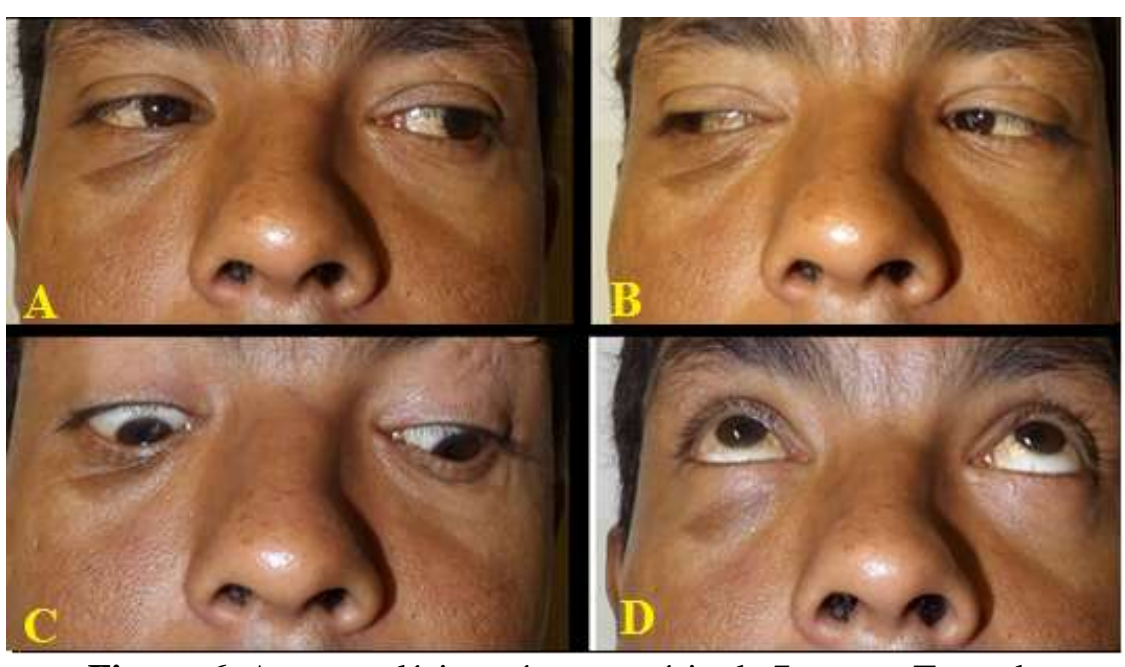

Figura 6. Aspecto clínico pós-operatório de 7 meses. Teste de mobilidade ocular demonstrando adequada função de musculatura extrínseca. A e B - mobilidade lateral; C e D - mobilidade vertical

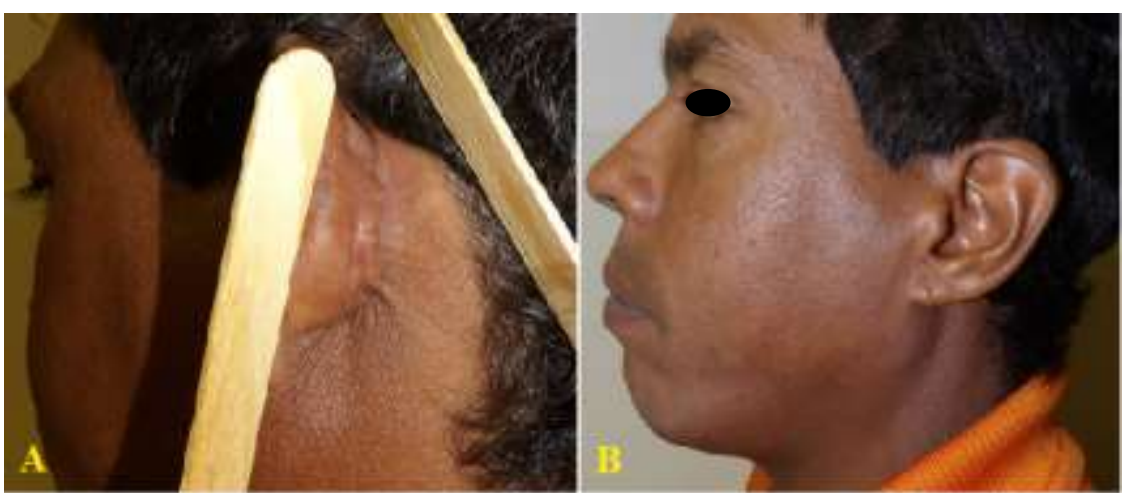

Figura 7. Pós-operatório de 7 meses. Aspecto clínico do pavilhão auricular. A - visão retroauricular demonstrando discreta cicatriz.

B - visão lateral demonstrando ausência de defeito estético

A TC no pós-operatório de 9 meses, demonstrou adequada adaptação do enxerto ao leito receptor. No corte axial, foi observada boa projeção do globo ocular sem sinais de enoftalmia ou perda de conteúdo periorbitário (Figura 8).

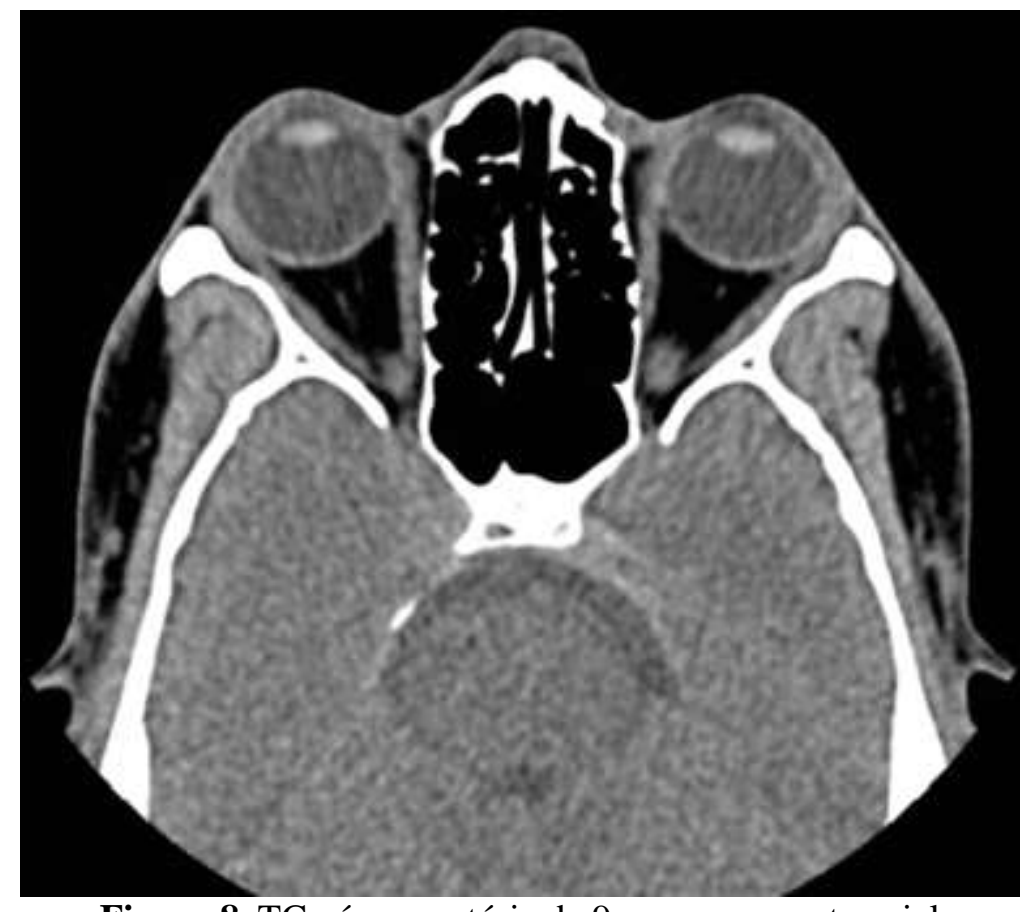

Figura 8. TC pós-operatória de 9 meses em corte axial evidenciando simetria em projeção do globo ocular

$\mathrm{Na}$ TC em corte coronal e sagital, foi observado seio maxilar sem evidências de herniação do conteúdo orbitário e adequado reparo em AO (Figura 9). 


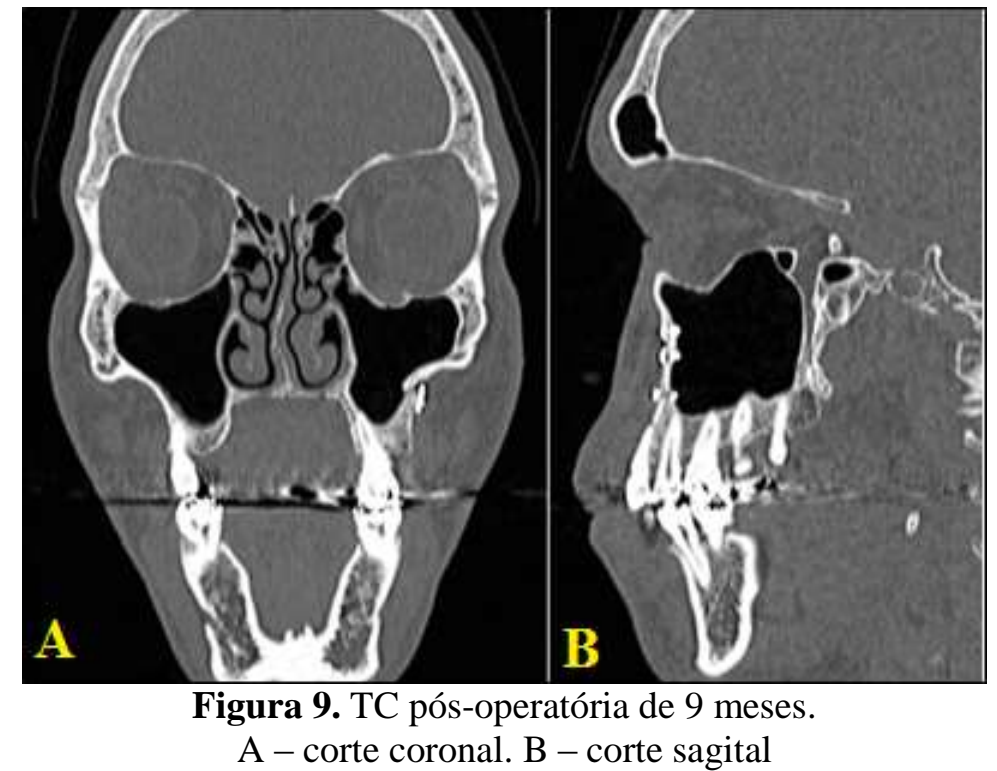

\section{DISCUSSÃO}

Para o tratamento das fraturas orbitárias um adequado conhecimento tridimensional das quatro paredes orbitais assim como de seu conteúdo, anatomia e estruturas adjacentes se faz necessário, a fim de proporcionar simetria e funcionalidade ao arcabouço facial. Tais reconstruções visam à reposição dos conteúdos orbitários herniados a fim de evitar enoftalmia, diplopia e distopia com retorno as suas funções fisiológicas ${ }^{15,16}$, fato este observado no caso clínico apresentado.

A inobservância de alterações clínicas em fraturas do complexo zigomático maxilar assim como o não tratamento precoce destas deformidades faciais por vezes levam ao desenvolvimento de sequelas de difícil resolução como distopia orbitária, enoftalmia e diplopia por disfunção de músculos extra-oculares, pósoperatórias, sejam parestesia do nervo infra-orbitário, encarceramento nervoso, hemorragia, ou mesmo injúria a nervos motores ${ }^{17,18,19}$.

Mesmo sem evidência de perda de substância do $\mathrm{AO}$ as fraturas do mesmo devem ser reparadas precocemente, com ou sem diplopia e/ ou enoftalmia, como denotado por Vieira et al. ${ }^{20}$ e Hammer ${ }^{18}$, assim como ocorreu no caso relatado. A herniação dos tecidos orbitais, através dos defeitos em assoalho pelo deslocamento dos fragmentos ósseos do rebordo infraorbital e a aderência de musculatura à periórbita, justificam o procedimento cirúrgico.

Na literatura há uma grande variedade de materiais autógenos, alógenos e aloplásticos relatados com considerável sucesso em reconstruções de AO. O material ideal deve ser facilmente moldável para se encaixar no defeito e anatomia orbital, facilmente fixado in situ, não propenso a migração, ser osteoindutor, bioabsorvível com um mínimo de reação do organismo, biocompatível, disponíveis em quantidade suficiente e forte o suficiente para suportar o conteúdo orbital e as respectivas forças de compressão ${ }^{13,16}$.

A decisão de se utilizar material autógeno ou aloplástico depende do tamanho do defeito, da preferência e experiência do cirurgião, da extensão de outras injúrias, do tempo de operação e do custo. ${ }^{10,21,22}$ Tendo o enxerto autógeno algumas vantagens em relação ao aloplástico, pois eventualmente formaria uma união com o osso adjacente ${ }^{23}$ fato que corrobora com a escolha aqui apresentada.

Baumann et al..$^{24}$ e Bande et al. ${ }^{12}$ afirmaram que apesar das vantagens apresentadas pelos materiais aloplásticos, sendo a principal delas a ausência de morbidade adicional proveninente ao leito doador, tais enxertos devem ser utilizados com cautela, uma vez que se comportam como corpos estranhos permanentes, sendo passíveis de complicações como infecção ou extrusão, mesmo após anos in situ.

Dentre os enxertos autógenos, os obtidos de cartilagem são os menos vascularizados, assim, há aumento da sua sobrevida, sendo a sua reabsorção menor do que ocorre nos enxertos ósseos. As cartilagens nasoseptal e do pavilhão auricular são enxertos com alta previsibilidade de duração e adaptação nos defeitos de AO. Além disso, as áreas doadoras destas cartilagens estão próximas ao local receptor, e podem ser alcançadas sem muito tempo adicional e alterações do posicionamento do paciente, do cirurgião, ou de equipe durante $\mathrm{o}$ ato cirúrgico ${ }^{13,35}$.

Segundo Özyazgan et al. ${ }^{36}$ e Talesh et al. ${ }^{13}$ o enxerto de cartilagem auricular agrega tanto as vantagens dos enxertos ósseo autógenos como dos materiais aloplásticos. Sua adaptação, maleabilidade e facilidade de conformação ao leito receptor em menor tempo cirúrgico equiparam-se aos materiais aloplásticos, e se mostram melhores que os enxertos ósseos autógenos, pois além de serem biocompatíveis, resistentes à infecção e à migração, características inerentes aos enxertos autógenos, os de cartilagem possuem menor morbidade cirúrgica, por não necessitarem de osteotomias e nem da obrigatoriedade de fixação, como ocorre com os enxertos ósseos.

A cartilagem auricular é usada com sucesso, mas complicações como deslocamento do enxerto são reportadas por alguns autore ${ }^{25}$, porém o uso da cartilagem auricular tem aplicação larga em pequenos defeitos do assoalho, até $2 \mathrm{~cm}^{2},{ }^{13,14,26}$ como são as fraturas blow-out ${ }^{18}$.

No caso relatado, o enxerto foi aposicionado sobre o assoalho orbital sem a necessidade de fixação como preconizado por Hammer ${ }^{18}$ em virtude da satisfatória adaptação ao defeito ósseo. No entanto, Özyazgan et al. ${ }^{26}$ observaram em dois pacientes, após três meses de pósoperatório, que o enxerto era palpável no rebordo infraorbitário, o que não foi observado no caso relatado nesse trabalho.

A cartilagem auricular como demonstrado por Constantian ${ }^{27}$, Ozyazgan et al. ${ }^{26}$, D'Ávila et al. ${ }^{16}$, Talesh et al. ${ }^{13}$, Mendonça et al. ${ }^{19}$, Bayat et al. ${ }^{28}$ e Mendonça et al. ${ }^{29}$ é sim bem indicada para reconstruções de pequenos defeitos no AO, sobretudo em virtude da sua forma 
semelhante ao assoalho, maleabilidade e força para resistir ao conteúdo orbitário. Os mesmos autores referem ainda a praticidade, rapidez para obtenção deste enxerto e bom resultado estético-funcional, o que ficou evidente com o caso apresentado.

\section{CONCLUSÃO}

A reconstrução do $\mathrm{AO}$ apresentada neste trabalho, com a utilização de cartilagem auricular, obteve bons resultados seja na função ou estética do paciente com ausência de intercorrências ou complicações.

\section{REFERÊNCIAS}

1. Baino F. Biomaterials and implants for orbital floor repair. Acta Biomater. 2011 Sep;7(9):3248-66.

2. Gierloff M, Seeck NG, Springer I, Becker S, Kandzia C, Wiltfang J. Orbital floor reconstruction with resorbable polydioxanone implants. J Craniofac Surg. 2012 Jan;23(1):161-4.

3. Hwang K, You SH. Analysis of facial bone fractures: An 11-year study of 2,094 patients. Indian J Plast Surg. 2010 Jan;43(1):42-8.

4. Yavuzer R, Tuncer S, Basterzi Y, Isik I, Sari A, Latifoglu O. Reconstruction of orbital floor fracture using solvent preserved bone graft. Plast Reconstr Surg. 2004 jan;113(1):34-44.

5. Tuncer S, Yavuzer R, Kandal S, Demir YH, Osmen $\mathrm{S}$, Latifoglu $\mathrm{O}$, et al. Reconstruction of traumatic orbital floor fractures with resorbable mesh plate. J Craniofac Surg. 2007 May ;18(3):598-605.

6. Fonseca RJ, Walker RVW. Oral and Maxillofacial Trauma. 2nd ed. St. Louis: Wb Saunders; 1997.

7. Ellis E 3rd, Tan Y. Assessment of Internal orbital reconstructions for pure blow-out fractures: cranial bone grafts vs titanium mesh. J Oral Maxillofac Surg. 2003 Apr; 61(4):442-53.

8. Gosau M, Schöneich M, Draenert FG, Etti T, Driemel O, Reichert TE. Retrospective analysis of orbital floor fractures - complications, outcome, and review of literature. Clin Oral Investig. 2011 Jun; 15(3):305-13.

9. Ezzat WF, El-Hasan MA, Rabie H. Validity and accuracy of subciliary endoscopic-aided repair of orbital floor fractures. Eur Arch Otorhinolaryngol. 2011 Jun;268(3):935-40.

10. Bourguignon Filho AM, Costa AT, Ibrahim D, Blaya DS, Viegas VN, Oliveira MG. Fraturas orbitárias blowout: tratamento com telas de titanio. Rev Cir Traumatol Buco-Maxilo-Fac. 2005;5(3):35-42.

11. Totir M, Ciuluvica R, Dinu I, Careba I, Gradinaru S. Biomaterials for orbital fractures repair. J Med Life. 2015 Jan-Mar;8(1):41-3.

12. Bande CR, Daware S, Lambade P, Patle B. Reconstruction of orbital floor fractures with autogenous bone graft application from anterior wall of maxillary sinus: a retrospective study. J Maxillofac Oral Surg. 2015 Sep; 14(3):605-10.

13. Talesh KT, Babaee S, Vahdati SA, Tabeshfar Sh. Effectiveness of a nasoseptal cartilaginous graft for repairing traumatic fractures of inferior orbital wall. Br J Oral Maxillofac Surg. 2009 Jan;47(1):10-3.

14. Castellani A, Negrini S, Zanetti U. Treatment of orbital floor blowout fractures with conchal auricular cartilage graft: a report on 14 cases. J Oral Maxillofac Surg. 2002 Dec; 60(12):1413-7.

15. Folkestad L, Granström G. A prospective study of orbital fracture sequelae after change of surgical routines. J Oral Maxillofac Surg. 2003; 61(9):103844.

16. D’Ávila LRN, Valadares AM, Oliveira MAM, Ribeiro Neto N, Macêdo Sobrinho JB. Tratamento de fratura blow-out com enxertos autógenos de cartilagem da concha auricular. Rev Cir Traumatol Buco-Maxilo-Fac. 2009;9(4):9-14.

17. Chang EW, Manolidis S. Orbital floor fracture management. Facial Plast Surg. 2005 Aug; 21(3):207-13.

18. Hammer B. Fraturas orbitárias: diagnóstico, tratamento cirúrgico, correções secundárias. São Paulo:Santos; 2005. p.2-5.

19. Mendonça JCG, Oliveira JGP, Lopes HB, Valente F. Reconstrução de assoalho de órbita com enxerto autógeno de cartilagem auricular. Rev Bras Cir Craniomaxilofac 2009;12(4):188-91.

20. Vieira EH, Gabrielli MFR, Gabrielli MAC, Barbeiro RH. Reconstrução do assoalho orbitário com enxertos ósseos. Rev APCD. 1996;50(2):164-9.

21. Rawashdeh MA, Telfah H. Secondary alveolar bone grafting: the dilemma of donor site selection and morbidity. $\mathrm{Br} \mathrm{J}$ Oral and Maxillofac Surg. 2008;46(8):665-70.

22. Tavares SSS, Tavares GR, Paiva MAF, Dias-Ribeiro E, Rocha JF. Reconstrução de assoalho de órbita com enxerto autógeno: relato de caso. Rev Odontol Univ Cid São Paulo. 2010; 22(3): 269-75.

23. Oliveira RB, Silveira RL, Machado RA, Nascimento MMM. Utilização de diferentes materiais de reconstrução em fraturas do assoalho de órbita: relato de seis casos. Rev Cir Traumatol Buco-Maxilo-Fac. 2005;5(3):43-50.

24. Baumann A, Ewers R. Transcaruncular approach for reconstruction of medial orbital wall fracture. Int $\mathrm{J}$ Oral Maxillofac Surg. 2000;29(4):264-7.

25. Courtney DJ, Thomas S, Whitfield PH. Isolated orbit blowout fractures: survey and review. $\mathrm{Br} \mathrm{J}$ Oral Maxillofac Surg. 2000 Oct;38(5):496-503.

26. Ozyazgan I, Eskitasçioglu T, Baykan H, Coruh A. Repair of traumatic orbital wall defects using conchal cartilage. Plast Reconstr Surg. 2006 Apr; 117(4):1269-76; 
27. Constantian MB. Use of auricular cartilage in orbital floor reconstruction. Plastic Reconst Surg. 1982 Jun;69(6):951-5.

28. Bayat M, Momen-Heravi F, Khalilzadeh O, Mirhosseni Z, Sadeghi-Tari A. Comparison of conchal cartilage graft with nasal septal cartilage graft for reconstruction of orbital floor blowout fractures. $\mathrm{Br} \mathrm{J}$ Oral Maxillofac Surg. 2010 Dec;48(8):617-20.

29. Mendonça JCG, Oliveira MM, Mazocatto DC, Gaetti Jardim EC. Reconstrução de fratura de assoalho orbital com uso de enxerto autógeno de cartilagem auricular: relato de caso. Arch Health Invest. 2015 ;4(1):26-30.

\section{CONFLITO DE INTERESSES}

Os autores declaram não haver conflitos de interesse.

\section{AUTOR PARA CORRESPONDÊNCIA}

Ellen Cristina Gaetti Jardim

ellengaetti@gmail.com
Submetido em 25/08/2016 Aceito em 13/09/2016 